REVISTA DE DERECHO UNED, núm. 5, 2009

\title{
ACTOS PROCESALES Y FIRMA ELECTRÓNICA
}

\author{
Por Corazón Mira Ros \\ Profesora Titular de Derecho Procesal (UNED)
}

Resumen: El fenómeno de la metamorfosis de la Administración Pública en una administración electrónica ha alcanzado también (como no podía ser de otro modo) a la Administración de Justicia, transformando sustancialmente, sobre todo, la organización y el funcionamiento de la oficina judicial, con la generalización de las comunicaciones electrónicas y de los documentos judiciales electrónicos y, al mismo tiempo, afectando a múltiples aspectos del proceso. Surge así una forma renovada de expresión de los actos procesales, la que resulta de su realización por medios electrónicos, que esconde la exigencia de un nuevo formalismo procesal, de carácter técnico, relativo a la firma digital y a los mecanismos que van a permitir en el proceso asegurar la autenticidad e integridad de las actuaciones electrónicas y el cumplimiento de los requisitos legalmente establecidos.

Palabras clave: expediente judicial electrónico, actos procesales electrónicos, actas electrónicas, comunicaciones procesales electrónicas, LexNet, Nueva Oficina Judicial, documentos públicos electrónicos, firma electrónica.

Abstract: The transformation of the public Administration in an electronic Administration has achieved also (as it could not be of another way) to the Administration of Justice, transforming especially the organization and the operation of the judicial office, with the generalization of the electronic communications and electronic judicial documents and, at the same time, affecting to multiple aspects of the process. A renewed form from expression of the procedural acts arises therefore, the one that results from its accomplishment by electronic means, that the exigency of a new procedural 
formalism hides, of technical character, regarding the digital signature and to the mechanisms that are going to allow to assure the authenticity and integrity of the electronic activities and the fulfillment of the legally established requirements.

Key words: electronic judicial file, electronic procedural acts, electronic acts, electronic procedural communications, LexNet, New Judicial Office, documents electronic public, electronic signature.

Sumario: I. Introducción.-II. La sociedad de la información, el documento electrónico y la firma electrónica.-II.1. El documento electrónico: concepto y notas esenciales. a) La grafía binaria. b) La inmaterialidad del documento electrónico. c) La ausencia de la firma manuscrita.-II.2. La firma electrónica.-II.3. La administración electrónica.-III. La realización de actos procesales por medios electrónicos.-III.1. Los actos de comunicación telemáticos: el sistema LexNet. a) La presentación electrónica de escritos y documentos. b) El traslado de copias. c) El envío de comunicaciones.-III.2. La prueba documental electrónica. a) La presentación de documentos. b) La impugnación de documentos.-III.3. La utilización de los medios técnicos de filmación y reproducción de la imagen y el sonido.III.4. La documentación de los actos procesales: la grabación en soporte audiovisual de los actos orales. a) La subsistencia del acta escrita. b) La firma electrónica del Secretario Judicial.

\section{INTRODUCCIÓN}

La adaptación del proceso civil a la nueva sociedad de la información ha orientado en los últimos años una amplia acción legislativa $^{1}$ que, al final, pretende generalizar el uso de las nuevas tecnolo-

1 Desde 1997 a 2007, se han establecido las bases jurídicas organizativas y tecnológicas para la adecuación del proceso a la administración electrónica a través de iniciativas recogidas, a grandes rasgos, en el Libro Blanco de la Justicia (1997), en la Carta de Derechos de los Ciudadanos ante la Justicia (2002), en el R.D. 937/2003, de Modernización de los Archivos Judiciales, en la L.O. 19/2003, de 23 de Diciembre, de Modificación de la L.O. del Poder Judicial y, como corolario tecnológico, en el R.D. 84/2007, de 26 de enero, sobre la implantación en la Administración de Justicia del sistema LexNet, cuyo desarrollo se ha acometido recientemente por la Ley 41/2007, de 7 de diciembre, sobre Regulación del Mercado Hipotecario, que modifica la vigente LEC, dando nueva regulación a diversas normas de su articulado. Cabe, igualmente, destacar dentro de este elenco legislativo el ACUERDO de 20 de septiembre de 2006, del Pleno del Consejo General del Poder Judicial, de creación de ficheros de carácter personal dependientes de los Órganos Judiciales, así como el recientísimo Real Decreto 95/2009, de 6 de febrero, por el que se regula el Sistema de Registros adminis- 
gías en la gestión del proceso, para alcanzar una realidad judicial informatizada.

Como primera manifestación de este fenómeno ${ }^{2}$, se han sentado las bases legales para que ahora todos los actos procesales y las resoluciones judiciales que conforman el proceso puedan realizarse electrónicamente, o transformarse en documentos judiciales electrónicos, cualquiera que sea la forma o el soporte en el que originariamente se hayan tramitado. Surge así una nueva forma de expresión de los actos procesales, la que resulta de su sustanciación o incorporación al proceso por medios electrónicos, como una tercera vía frente al dualismo clásico de avance del proceso sobre los principios de oralidad o de escritura. La apertura de esa vía informática puede ser, según algunos, la panacea de todos los males cifrados históricamente en la consabida ralentización de la Justicia. Pero detrás de esa digitalización del proceso civil y su «instantaneidad» se esconde la exigencia de un nuevo formalismo procesal, falto todavía de un desarrollo doctrinal, ahora tan urgente como necesario. El mayor esfuerzo de la dogmática procesal va a girar durante los próximos años en torno al encaje rudimentario de los elementos del nuevo sistema procedimental, como las comunicaciones telemáticas, la firma digital reconocida que sirva de medio para garantizar la autenticidad e integridad de las declaraciones electrónicas y el cumplimiento de los requisitos legalmente establecidos, el alcance de la publicidad telemáticamente accesible de las actuaciones y la interconectividad de archivos.

trativos de apoyo a la Administración de Justicia. Finalmente, un Plan Estratégico para la Modernización del Sistema de Justicia (2009-2012), aprobado el pasado 18 de septiembre por el Consejo de Ministros, sirve de colofón en el propósito de lograr una justicia tecnológicamente avanzada.

${ }^{2}$ En una afinada exposición del tema, el Prof. ORTELLS RAMOS enseña que existen dos formas fundamentales de incidencia de las NTI en la gestión jurisdiccional: (1) Las NTI como medio o instrumento para la realización de la actividad procesal, tanto del tribunal y de sus auxiliares, como de las partes. Señala el autor que «Los grados posibles de utilización de las nuevas tecnologías como instrumento de la actividad procesal son muy diversos. Abarcan desde su empleo como instrumento de trabajo para la elaboración material de actos legalmente previstos en la forma tradicional (por ejemplo redacción de actos escritos mediante programa de tratamiento de texto), hasta la creación de una nueva forma de procedimiento - distinta de la oralidad y de la escritura-, pasando por su uso en los actos de comunicación procesales». (2) Las NTI como generadoras de nuevas realidades sociales y consecuentemente jurídicas, lo que supone la existencia de nuevas materias litigiosas, sobre las que versará la actividad procesal. ORTELLS RAMOS, M., Incidencia de las nuevas tecnologías en el proceso jurisdiccional. Especial análisis de las cuestiones referentes a la prueba, a las medidas cautelares y a las comunicaciones procesales, en las «XI Jornadas Nacionales y XVIII Jornadas Iberoamericanas de Derecho Procesal» Libro de Ponencias, F.C.U., Mdeo., 2002, págs. 610-611. 
Para el estudio de los actos procesales electrónicos se hace obligado entonces contextualizar su todavía embrionaria regulación dentro del panorama general de una nueva sociedad de la información, como la que contribuyen a definir las disposiciones normativas a las que haremos referencia, sobre la base de la generalización de los documentos electrónicos y de la firma digital, y con el trasfondo de una Administración también electrónica (de la que forma parte la Administración de Justicia).

\section{LA SOCIEDAD DE LA INFORMACIÓN, EL DOCUMENTO ELECTRÓNICO Y LA FIRMA ELECTRÓNICA}

\section{II1. El documento electrónico: concepto y notas esenciales}

Las dos primeras ventajas que supuso el empleo de la informática como instrumento de tratamiento de textos y como sistema de organización o gestión de archivos, siendo tan inmensas, en seguida quedaron superadas por la importancia del ordenador como medio de conexión a internet ${ }^{3}$. El fenómeno que, a partir de aquí, se ha propagado con una fuerza vertiginosa ha sido esa capacidad de los ordenadores de conectarse entre sí por medio de la red de redes. Miles de millones de personas en todo el globo, desde una pantalla de ordenador, comparten ahora en milésimas de segundo todo tipo de información. Esa transformación global se ha venido en llamar así, con razón, la de la «sociedad de la información». En ella, en esa sociedad global intercomunicada, son, en realidad, los ordenadores los que se conectan o se comunican entre sí, compartiendo un mismo lenguaje, que puede tener complejas y muy diversas codificaciones -Word, java, PDF, hash, etc.-, pero que no son sino las variantes de un nuevo lenguaje universal: el llamado lenguaje de los ordenadores, utilizado constantemente en el comercio electrónico, y también como herramienta para almacenar, conservar y transmitir información de unos sujetos a otros, creando un nuevo tipo de documento «sin papel» ${ }^{4}$.

3 Vid. MARTÍNEZ VALERO, J. y ESEBBAG BENCHIMOL, C., Navegadores en Internet. Word Wide Web, Madrid. 1996; VILCHES TRASIERRA, A. J., Aproximación a la Sociedad de la Información: Firma, Comercio y Banca electrónica. Centro de Estudios Registrales. Madrid. 2002; y también VVAA, Comercio electrónico en Internet, . Madrid. 2001.

${ }_{4}$ Sobre la idea prueba documental en soporte papel versus documento electrónico pueden consultarse los siguientes autores: MONTERO AROCA, J., «Nociones generales sobre la prueba (entre el mito y la realidad), (Ponencia primera al curso La prueba, dentro del ciclo «Nueva ley de Enjuiciamiento Civil», Consejo General del poder Judicial, 22 a 25 de mayo de 2000; en Cuadernos de Derecho Judicial, VII, 2000, 


\section{a) La grafía binaria}

El problema es que ese lenguaje tiene su propio alfabeto (en realidad, sólo de dos letras, aunque su posibilidad de combinación sea infinita), formado por un sistema binario capaz de componer impulsos o estímulos eléctricos o fotosensibles a partir de cuya descomposición y recomposición informática grabada en un formato electrónico, como es el disco duro de un ordenador, se genera y almacena toda la información. Por ello, el idioma informático es algo incorporado al disco duro de un ordenador a través de un código ininteligible (salvo para quien sea un experto en informática). Su visualización en pantalla bajo la forma de un texto de lectura comprensible - como explica MADRIDEJOS FERNÁNDEZ ${ }^{5}$ - sólo es una traducción en lenguaje alfabético común, que supone una segunda descodificación, hecha también informáticamente, de la información codificada en clave binaria dentro del disco duro del ordenador.

\section{b) La inmaterialidad del documento electrónico}

Mientras el texto escrito en papel es, realmente, un documento (del latín, docere, enseñar), porque enseña lo que contiene, y en él hay identidad entre lo grabado y lo exteriorizado ${ }^{6}$, por el contrario, lo almacenado en soporte electrónico no se exterioriza, y si lo hace, no hay entonces identidad entre lo conservado y lo exteriorizado: lo conservado constituye un archivo en sistema binario, mientras lo exteriorizado adopta la forma de escritura con las letras de nuestro alfabeto, pero son signos de escritura que no existen en la realidad natural, no tienen base material tangible, sino virtual.

\section{c) La ausencia de firma manuscrita}

A esa falta de recognoscibilidad directa del texto en soporte electrónico se suma otra diferencia respecto del texto documentado en

pp. 17-66); DE LA OLIVA SANTOS, A., Derecho Procesal Civil, El proceso de declaración conforme a la ley 1/2000 de 7 de enero, de Enjuiciamiento Civil, con Díez.Picazo Jiménez, I., Madrid, 2000, p. 619; GUZMÁN FLUJA, V., "Prueba Documental», volumen III, pp. 2351-52, en El proceso civil. Doctrina, Jurisprudencia y formularios (coord. Escribano Mora), Valencia 2001.

5 MADRIDEJOS FERNÁNDEZ, A., La copia notarial electrónica. El Notario del siglo XXI. Ensayos de actualidad. Colegio Notarial de Madrid, Madrid, 2007, pág. 37.

6 TORRES LANA, J.-A., "Formas del negocio y nuevas tecnologías», en Revista de Derecho Privado, julio-agosto, 2004, págs. 489 y ss. 
papel, que es el sistema de asunción o imputación de su autoría, la firma ${ }^{7}$. Ningún texto tiene valor de declaración mientras carece de autor. Con su firma, el declarante asume la autoría de la declaración. Hasta entonces un texto sin firmar sólo es un borrador o una declaración en proyecto. La firma individualiza la declaración y, al aparecer manuscrita en el propio documento, permite reconocer a su autor. Por el contrario, el texto derivado de un soporte electrónico, al tener una formulación sólo virtual, sin base material tangible, carece por igual razón de firma reconocible materialmente.

La identificación del declarante y la fijación del contenido íntegro de su declaración sólo puede formularse como una conjetura presumible a partir de indicadores que permitan descifrar las claves de encriptación asignadas a un determinado usuario, para asegurar la autenticidad e integridad de su declaración bajo complejas fórmulas en forma de algoritmos matemáticos, lo que se conoce como creación de un dispositivo de firma electrónica, es decir, un dispositivo que permita sostener esa suposición con alto grado de fiabilidad ${ }^{8}$.

\section{II.2. La firma electrónica}

La denominada firma electrónica avanzada ${ }^{9}$ permite la posibilidad de relacionar ese dispositivo de manera fidedigna con determinado titular, pues está vinculado al firmante de una manera inequívoca, haciendo inalterable el contenido de su declaración, por medio de un mecanismo que el firmante mantiene bajo su exclusivo control, de modo semejante al dispositivo que históricamente permitía sellar una declaración, imputándola al titular del sello.

Si la titularidad o pertenencia de ese dispositivo de creación de firma electrónica con relación a determinado usuario puede además certificarla un tercero de confianza (consistente en alguna de las entidades prestadoras de servicios de certificación, constituidas e inscritas con los requisitos legales ${ }^{10}$ ) la firma electrónica avanzada al-

7 RODRÍGUEZ ADRADOS, A., Firma electrónica y documento electrónico. El Notario del siglo XXI. Ensayos de actualidad. Colegio Notarial de Madrid, Madrid, 2007, págs. 36 y ss.

8 RODRÍGUEZ ADRADOS, A., La seguridad de la firma electrónica. Consecuencias de su uso por un tercero. Escritura Pública. Ensayos de actualidad. Consejo General del Notariado, Madrid, 2005, págs. 9 y ss.

9 RODRÍGUEZ ADRADOS, en Firma electrónica..., op. cit., págs. 56 y ss.

10 En España, a poco de vencer el plazo fijado para su incorporación, se aprobó el Real Decreto-Ley 14/1999, de 17-09-1999112, luego sustituido por la Ley 59/2003, de 
canza entonces mayor grado de certidumbre, denominándose firma electrónica reconocida ${ }^{11}$, que tendrá respecto de los datos consignados en forma electrónica el mismo valor que la firma manuscrita en relación con los consignados en papel (art. 3.4 de la Ley 59/2003, de Firma Electrónica, tras la modificación operada por la Ley 56/2007, de 28 de diciembre, de Impulso de la Sociedad de la Información) ${ }^{12}$.

En cualquiera de las dos modalidades descritas, la firma electrónica es siempre un medio de identificación del firmante conforme con lo establecido en el art. 3 de la Ley 59/2003, de 19 de diciembre. Pero existen otros sistemas adecuados también para garantizar igualmente la identificación de los declarantes y, en su caso, la autenticidad e integridad de los documentos electrónicos, que se encuentran expresamente admitidos en otras leyes ${ }^{13}$.

19-12-2003, 113. En España, a poco de vencer el plazo fijado para su incorporación, se aprobó el Real Decreto-Ley 14/1999, de 17-09-1999, 112, luego sustituido por la Ley 59/2003, de 19-12- 2003113.MARTÍNEZ NADAL, A., «Firma electrónica, certificados y entidades de certificación», en Revista de la Contratación Electrónica, n. ${ }^{\circ} 27$, mayo2002, págs. 59 y ss.

11 RODRÍGUEZ ADRADOS, en Firma electrónica..., op. cit., págs. 59 y ss.

12 En la Unión Europea rige la Directiva 1999/93/CE del Parlamento Europeo y del Consejo, del 13-12-1999. La Directiva define a la firma electrónica como «los datos en forma electrónica anejos a otros datos electrónicos o asociados de manera lógica con ellos, utilizados como medio de autenticación» (art. $2^{\circ}$, núm. 1); y a la firma electrónica avanzada, como la firma electrónica que cumple con los siguientes requisitos: (a) estar vinculada al firmante de manera única, (b) permitir la identificación del firmante, (c) haber sido creada utilizando medios que el firmante puede mantener bajo su exclusivo control, y (d) estar vinculada a los datos a que se refiere de modo que cualquier cambio ulterior de los mismos sea detectable» (art. $2^{\circ}$ núm. 2). Se señala que de la recta interpretación de la norma surge un tercer tipo, la firma electrónica avanzada cualificada, basada en un certificado reconocido y creada por un dispositivo seguro de creación de firma. Con anterioridad a la Directiva algunos países de la Unión ya habían aprobado leyes de firma electrónica: Alemania dictó la Gesetz zur digitalen signatur, de 13-06-1997, verdadero modelo a nivel comparado; e Italia consagró una regulación en el art. 15 de la Legge-Delega de 15-03-1997 y el Regolamento recante criteri e modalità per la formazione, l'archiviazione e la trasmisione di documenti con strumenti informatici e telematici, aprobado por Decreto de 10-11-1997.

${ }^{13}$ La Ley 11/2007, de acceso electrónico de los ciudadanos a los servicios públicos establece un desglose, diferenciando los sistemas de firma electrónica según se encuentren a disposición de los ciudadanos o, por el contrario, se prevean como modo de identificar y autenticar los documentos producidos por la Administración Pública. Como elemento común en ambas series aparece el DNI electrónico (art. 13 y 19 de la Ley 11/2007). Se trata de un documento que al llevar incorporado un certificado de autenticación y otro de firma electrónica, acredita electrónicamente la identidad personal de su titular incluidos los funcionarios y permite, al mismo tiempo, firmar electrónicamente documentos, asegurando su integridad, procedencia y la autenticidad de su origen. Para los ciudadanos, además de los sistema de firma electrónica avanzada y reconocida, la ley se sirve de una cláusula abierta, a través de la cual da 


\section{II.3. La administración electrónica}

La regulación de la llamada firma electrónica y de los llamados documentos electrónicos ha sido abordada en nuestro ordenamiento por la Ley 59/2003, de 19 de diciembre, como una respuesta legislativa a la exigencia inaplazable (conforme al mandato de las Directivas europeas sobre comercio electrónico y firma digital) de dar seguridad jurídica a las comunicaciones electrónicas a través de Internet, de enorme difusión. Pero la red de redes ha transformado no sólo el mercado, por el avance incontenible de las transacciones telemáticas, sino la propia sociedad y las pautas de comportamiento de los ciudadanos, en sus relaciones privadas y frente a las Administraciones Públicas.

Una norma clave, en este contexto (en consonancia con el denominado "proyecto e-Europa» dentro del espacio de la Unión Europea,) ha sido la Ley 11/2007, de 22 de junio, sobre el Acceso Electrónico de los Ciudadanos a los Servicios Públicos. En ella se consagra, como principio rector de toda la organización y actividad administrativas, el derecho de comunicación electrónica del ciudadano con la Administración Pública $\left(\right.$ art. $\left.1^{\circ}\right)$. Corolario de ese derecho es la correlativa obligación de la Administración Pública de transformarse en una Administración electrónica, haciendo posible, más allá de la mera práctica de comunicaciones y notificaciones por vía electrónica, la implantación incluso de un «documento administrativo electrónico» (definido en el art. 29) y la obligatoria instrucción sobre soporte electrónico del conjunto de actuaciones integrantes del expediente administrativo (art. 32), así como la llevanza por medios electrónicos de los archivos y registros públicos, configurados legalmente como registros electrónicos de acceso telemático (art. 24), junto a un deber de interoperabilidad extensible a todas las oficinas públicas (art. 3) para hacer realidad el derecho del ciudadano a no aportar datos y documentos que obren en po-

entrada a la utilización para identificación de cualquier otro instrumento, como las claves concertadas en un registro previo, aportación de información conocida por ambas partes u otros sistemas no criptográficos (art. 16 de la Ley 11/2007). con carácter exclusivo para la actuación administrativa automatizada, la ley regula, en cambio, los sellos electrónicos, basados en certificados electrónicos que reúnen los requisitos exigidos por la legislación de firma electrónica y los códigos seguros de verificación, vinculados a la Administración Pública y, en su caso, a la persona firmante del documento. Por último, la ley valida los documentos electrónicos transmitidos en entornos cerrados de comunicaciones establecidos entre Administraciones Públicas, órganos y entidades de Derecho público, con tal de que la propia Administración (o a través de convenios, si los participantes pertenecen a distintas Administraciones), establezca las condiciones y garantías por las que se regirá la comunicación, siendo en tal caso necesario que se elabore una relación de emisores y receptores autorizados y la naturaleza de los datos a intercambiar. 
der de las Administraciones Públicas (art. 6). Y en este esfuerzo hacia esa nueva Administración electrónica el último hito lo ha marcado la edición - a partir del pasado día uno de diciembre- del propio Boletín Oficial del Estado en formato electrónico, un $B O E$ digitalizado, de acceso telemático y gratuito por todos los ciudadanos.

\section{LA REALIZACIÓN DE ACTOS PROCESALES POR MEDIOS ELECTRÓNICOS}

La admisión del formato electrónico como vehículo de la actividad procesal parece indiscutible. El punto de referencia en este sentido se encuentra en los art. 230 y 271 de la LOPJ, tras su reforma por la Ley 16/1994, de 8 de noviembre, al contemplar, de manera genérica, el uso de medios técnicos, electrónicos, informáticos y telemáticos, compatibles entre sí, para que tanto los órganos judiciales como las personas que demanden ante ellos la tutela judicial efectiva de sus derechos e intereses legítimos desarrollen la actividad procesal.

Aunque la aplicación del principio de equivalencia entre el escrito electrónico y el escrito en soporte papel es ya una realidad irreversible, si acudimos a la LEC, sin embargo, enseguida se percibe el reto de la electronificación del proceso civil como una cuestión de límites, que aconseja distinguir entre la actividad de las partes en el proceso y la del propio Juez o el Secretario y sus medios auxiliares.

\section{III.1. Los actos de comunicación telemáticos: el sistema LexNet}

LexNet es un sistema de comunicaciones electrónicas para la Administración de Justicia, implantado, de momento, en el territorio del Ministerio de Justicia, basado en un sistema de correo electrónico seguro que permite la comunicación bidireccional de las oficinas judiciales con los distintos operadores jurídicos, esto es, con los abogados y los procuradores, facilitando tanto la realización de los actos de comunicación procesal por los órganos judiciales como la presentación de los escritos y de los documentos y el traslado de las copias de los mismos por los profesionales del Derecho ${ }^{14}$.

${ }^{14}$ Los interlocutores en las comunicaciones telemáticas en el ámbito de la Administración de Justicia son los sujetos que intervienen en los procesos judiciales. Por una parte, están los Secretarios judiciales y los funcionarios de los cuerpos al servicio 
La validez del acto de comunicación dependerá entonces de que se garantice que el mensaje proviene efectivamente del que afirma ser su emisor, «que su contenido no ha sido alterado durante la transmisión, incluyendo los eventuales documentos adjuntos, es decir, que es auténtico y está íntegro, y que pueda constar fehacientemente, en este caso por los propios mecanismos de certificación del sistema, que la comunicación se ha enviado y recibido sin alteración posible en un determinado día y hora y por personas que pueden identificarse; además, el medio empleado ha de permitir que de todo lo antedicho pueda quedar constancia en los autos, y desde luego ha de mantener la necesaria confidencialidad ${ }^{15}$.

Para la consecución de todas estas finalidades, el sistema confía, primero, en la «firma electrónica reconocida» ${ }^{16}$, pues, como reza la Exposición de Motivos de la Ley 59/2003, de 19 de diciembre, de Firma Electrónica, «constituye un instrumento capaz de permitir una comprobación de la procedencia y de la integridad de los mensajes intercambiados a través de redes de telecomunicaciones, ofreciendo las bases para evitar el repudio, si se adoptan las medidas oportunas basándose en fechas electrónicas». En la intervención de un "tercero de confianza» ${ }^{17}$, en segundo lugar, como parte esencial del mecanismo de la firma electrónica reconocida y presupuesto de

de la Administración de Justicia que desempeñan sus funciones en la oficina judicial $y$, por otra parte, las personas que demandan la tutela judicial, los profesionales que les asisten y otras.

${ }^{15}$ Es un párrafo literal de DE HOYOS SANCHO M., «Hacia un proceso civil más eficiente: Comunicaciones telemáticas. El sistema Lexnet»; en Oralidad y Escritura en un proceso civil eficiente..., op. cit. págs. 94 y 95.

${ }_{16}$ Que se define en la propia Ley 59/2003, de 19 de diciembre, de firma electrónica - art. 3- como aquel conjunto de datos en forma electrónica que pueden ser utilizados como medio de identificación del firmante, que permite detectar cualquier cambio ulterior de los datos firmados, vinculada al firmante de manera única, así como a los datos a que se refiere, creada por medios que el firmante puede mantener bajo su exclusivo control, basada en un certificado reconocido y generada mediante un dispositivo seguro de creación de firma. Sobre otros sistemas electrónicos de identificación del firmante, véase MIRA ROS, C., El expediente Judicial electrónico, Madrid, 2009, págs. 6 y ss.

${ }^{17}$ Son concretamente las denominadas «entidades de certificación» o «prestadores de servicios de certificación», que se definen en la propia Ley 59/2003, de firma electrónica, - art. 2.2- como «aquella persona física o jurídica que expide certificados electrónicos o presta otros servicios en relación con la firma electrónica». Especialmente nos interesa la expedición por éstos de los denominados «certificados reconocidos» —arts. 11 y ss. de la Ley 59/2003-, que son aquellos emitidos previa comprobación de la identidad y demás circunstancias de los solicitantes — vgr.: pertenencia a un determinado colectivo profesional-, y que cumplen con los requisitos de fiabilidad y demás garantías exigidas por las leyes. 
su funcionalidad, y por consiguiente también del sistema Lexnet, que es por designación del Ministerio de Justicia la Fábrica Nacional de Moneda y Timbre y, finalmente, en la emisión de un «certificado de usuario», para vincular de alguna manera a los distintos operadores con sus respectivas claves personales y poder así tener la certeza de que el firmante es realmente quien dice $\operatorname{ser}^{18}$.

Para mayor seguridad, el sistema LexNet requiere también la existencia de una base de datos de cada usuario, es decir, la estructura de los órganos judiciales y de los Colegios Profesionales residen en un directorio LDAP, de forma que a aquellos usuarios que no se encuentren contenidos en el Directorio les resultará imposible acceder al sistema ${ }^{19}$.

18 Esta función aseguradora de la identidad del firmante, y eventualmente de su cualidad de funcionario o profesional en activo perteneciente a un determinado colectivo, corresponde a los prestadores de servicios de certificación reconocidos, que emitirán el correspondiente "certificado de usuario», el cual, junto con el «alta o validación» como usuario por el administrador competente, le permitirá operar dentro de la plataforma Lexnet haciendo uso de su propia tarjeta criptográfica. Actualmente se ha creado la tarjeta criptográfica CERES que cumple con todos los requisitos indispensables para ser considerada por las reglas europeas «Dispositivo seguro de creación de firma» Ver, por todo, DE HOYOS SANCHO M., "Hacia un proceso civil más eficiente: Comunicaciones telemáticas. El sistema Lexnet»; en Oralidad y Escritura en un proceso civil eficiente..., op. cit. págs. 94-95.

${ }_{19}$ Sucintamente, el procedimiento para la presentación de escritos y documentos, el traslado de copias y la realización de actos de comunicación procesal a través del sistema Lexnet, es el siguiente: Los usuarios del sistema dispondrán, como hemos indicado, de su correspondiente "tarjeta criptográfica», que en el caso de los Abogados y Procuradores coincidirá materialmente con su tarjeta profesional expedida por el respectivo Colegio, y en el caso de los Secretarios judiciales será una tarjeta específica para tal fin. En cualquier caso, dichos soportes deberán contener la "firma electrónica reconocida» que les acredita como usuarios del sistema, expedida por la correspondiente entidad de certificación -Ministerio de Justicia, Autoridad de Certificación de la Abogacía, F.N.M.T, entre otras- Además, y como paso previo a la utilización del sistema, los usuarios deberán solicitar el «alta» en el mismo con su certificado de usuario, lo que harán por medio de una conexión a la dirección web «justicia.es»o bien a través de los respectivos «portales» profesionales de los distintos operadores jurídicos reconocidos por el Ministerio de Justicia. Por otra parte, como es lógico, deberán disponer de un equipo informático con lector de este tipo de tarjetas y en el que se haya instalado el software preciso para su operatividad. Vid. DE HOYOS SANCHO, Hacia un proceso civil eficiente..., op. cit., pág. 98; también CREMADES GARCÍA, V. / ALACID BAÑO, L.M.: «Lexnet: el reto de las nuevas tecnologías en la Administración de Justicia», Revista de la Facultad de Ciencias Sociales y Jurídicas de la Universidad Miguel Hernández, núm. 2, 2007, pp. 46 y ss., esp. p. 52 y Anexo VI al RD 84/2007, y más ampliamente, una descripción muy gráfica del funcionamiento del sistema puede encontrarse en el «Manual de Procuradores» editado por el Consejo General de Procuradores de España y por el Ministerio de Justicia -www.cgpe.es—, o en el «Manual de usuarios de Lexnet. Versión 2.1» elaborado por Red Abogacía —www.redabogacia.org-. 
Finalmente, es esencial para la acreditación de la presentación telemática de escritos y documentos que el sistema devuelva al usuario un resguardo electrónico acreditativo de la correcta transmisión y, en todo caso, de la fecha y hora de la efectiva realización de la presentación en la Oficina Judicial.

Cuando se trate de los actos procesales de comunicación dirigidos a las partes intervinientes por el órgano judicial (Secretario Judicial) el sistema devolverá al remitente un resguardo electrónico, acreditativo de la remisión y puesta a disposición, en el que consten los siguientes datos: identidad del remitente y del destinatario, fecha y hora de su efectiva realización proporcionada por el sistema y tipo de procedimiento judicial, número y año al que se refiere. Y también un resguardo electrónico dirigido al remitente, reflejando el hecho de la recepción y la fecha y hora en que ha tenido lugar, quien así tendrá constancia de la recepción (art. 7 del Real Decreto 84/2007, de 26 de enero).

El desarrollo de las comunicaciones electrónicas a través del sistema LexNet ${ }^{20}$ en la gestión del proceso se acomete por medio de la reciente Ley 41/2007, de 7 de diciembre, sobre Regulación del Mercado Hipotecario, que, a través de su DF 6a , modifica la vigente LEC, dando nuevo redacción a diversas normas de su articulado ${ }^{21}$. De con-

${ }^{20}$ Bibliografía sobre Lexnet la podemos encontrar en PASTOR CREMADES GARCÍA, J.M., «Un paso importante hacia el proceso telemático en España: el sistema informático de telecomunicaciones lexnet para la presentación de escritos y documentos, el traslado de copias y la realización de actos de comunicación procesal por medios Telemáticos», en Oralidad y escritura en un proceso civil eficiente..., op. cit. pág. 130 y ss.; ALACID BAÑO, L. M., «Lexnet: el reto de las Nuevas Tecnologías en la administración de justicia», Revista de la Facultad de Ciencias Sociales y Jurídicas de la Universidad Miguel Hernández, núm. 2, 2007, pp. 46-58; DE HOYOS SANCHO, M., "Actos procesales de notificación y nuevas tecnologías», La Ley: Revista jurídica española de doctrina, jurisprudencia y bibliografía, núm. 2, 2003, pp. 1562-1570; DE HOYOS SANCHO, M., "Firma digital y comunicaciones procesales», Actualidad jurídica Aranzadi, núm. 571, 2003, pp. 4-5; GARRIDO CARRILLO, F. J., «El secretario judicial, clave en el nuevo modelo de oficina judicial tecnológicamente avanzada», Revista de la Facultad de Derecho de la Universidad de Granada, núm. 8, 2005, pp. 85-107; HUGUET TOUS, P. L., «Pistoletazo de salida para la presentación telemática de escritos en los órganos judiciales: el Consejo de Ministros aprueba el Real Decreto que regula la utilización del Sistema LEXNET», La Ley: Revista jurídica española de doctrina, jurisprudencia y bibliografía, núm. 4, 2007, pp. 1446-1448; y POZO MOREIRA, F. J., «La presentación de demandas y documentos y la realización de notificaciones en los Juzgados y Tribunales del Orden social por medios telemáticos: la reforma del Procedimiento civil y Laboral por la Ley 41/2007», Diario La Ley, núm. 6890, 2008.

${ }_{21}$ Vid. arts. 135, 151, 154, 162, 267, 268, 274, 276, 278 y 318 LEC, redactados con-

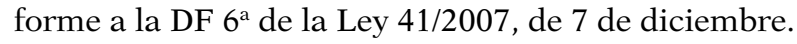


formidad con los nuevos preceptos, tres son los actos procesales que se van a ver afectados por el sistema LexNet: la presentación de escritos y documentos, el traslado de las copias y los actos de comunicación por parte del órgano jurisdiccional.

\section{a) La presentación electrónica de escritos y documentos}

A la vista del art. $1^{\circ}$ y el Anexo II del Real Decreto, antes citado, y del contenido del art. 135 LEC, en su nueva redacción, tras la ley 41/2007, la admisión del formato electrónico como modo de organización de la oficina judicial y vehículo operativo para la presentación en el proceso civil de los escritos, incluidos los actos procesales de alegación (presentación de los escritos de demanda y contestación a la demanda) parece indiscutible, igual que con relación a la incorporación al proceso de los documentos procesales y materiales que deben acompañar a la demanda.

Bastará, dice la LEC (a la vista del art. $1^{\circ}$ y el Anexo II del Real Decreto, antes citado, y del contenido del art. 135 LEC), con que las Oficinas Judiciales y los sujetos intervinientes en el proceso dispongan de medios técnicos que permitan el envío y la normal recepción de escritos iniciadores y demás escritos y documentos, de forma tal que esté garantizada la autenticidad de la comunicación, y quede constancia integra de la remisión y recepción íntegras y de la fecha en que se hicieron, es decir, con firma electrónica reconocida y contra un resguardo acreditativo del momento en que se hizo la presentación.

Del precepto citado se desprende que la Firma electrónica del demandante, con cada una de las formalidades que se exigen en el Real Decreto 84/2007, de 26 de enero, de Implantación del sistema Lexnet ${ }^{22}$, se constituye así en un presupuesto especial de admisibilidad de la demanda, un requisito formal que habrá de llevar incorporado no sólo el documento electrónico anexo en el que se contiene el propio acto

${ }^{22}$ El anexo IV del Real Decreto 87/2007, de Implantación del sistema LexNet establece los requisitos de acceso: 1 . Se admitirá, a los usuarios que se relacionan en el Anexo II, la presentación y recepción telemática de documentos mediante firma electrónica, basadas en un certificado que cumpla con la recomendación UIT X.509.V3 o superiores (ISO/IEC 9594-8 de 1997) o aquellas otras que pudieran ser publicadas en el Diario Oficial de la Unión Europea, de conformidad con lo previsto por la Ley 59/2003, de 19 de diciembre, de firma electrónica.2. A los efectos contemplados en el apartado anterior, serán válidos los certificados de usuario correspondientes al DNI electrónico o aquellos que cumpliendo los requisitos previstos en el apartado 1 de este Anexo sean expedidos por prestadores de servicios de certificación reconocido. 
procesal objeto de transmisión, sino también cada uno de los anexos donde aparezcan los documentos electrónicos que se adjuntan y que inexorablemente deben acompañar a la demanda y a la contestación a la demanda (un anexo por cada documento adjuntado). Por razones de eficacia del sistema, el control de este nuevo presupuesto procesal debiera haberse encomendado en el marco normativo de creación y complementación de la Nueva Oficina Judicial ${ }^{23}$, al Secretario Judicial, quien debiera poder inadmitir la demanda por no quedar suficientemente acreditada ab initio, en el momento de la presentación, la autenticidad, integridad y no repudio del acto procesal que se transmite electrónicamente.

La técnica para adjuntar documentos a los escritos electrónicos de iniciación del proceso, o a cualesquiera otros, consiste en los dispositivos de digitalización o escaneado de documentos que originariamente constan en soporte papel, como medio para obtener copias electrónicas que puedan transmitirse también electrónicamente a los destinatarios. Se trata de una medida para evitar que la presentación de documentos interrumpa la operatividad y la eficacia del sistema de comunicaciones electrónicas, pero de conformidad con el art. 162.2 de la LEC, no impide que, a instancia de las partes, del Ministerio Fiscal o de oficio por el propio Tribunal, en los procesos de familia incapacidad y filiación, los documentos en su soporte papel original puedan ser aportados en el plazo o momento procesal que a tal efecto se señale, cuando sea necesario a efectos de prueba o el cumplimiento de los requisitos legales exija disponer de los documentos originales o de copias fehacientes.

La cuestión relativa a la fecha de validez del acto que ha sido transmitido electrónicamente se resuelve en el art. 135.5 LEC, al disponer que «se tendrán por presentados, a efectos de ejercicio de los derechos y de cumplimiento de deberes» en la fecha y hora que conste en el resguardo acreditativo de su presentación. En caso de que la presentación tenga lugar en día u hora inhábil a efectos procesales conforme a la ley, se entenderá efectuada el primer día y hora hábil siguiente». Igualmente, dispone el precepto que «cuando la presentación de escritos perentorios dentro de plazo, por los medios técnicos a que se refiere este apartado, no sea posible por interrupción no planificada del servicio de comunicaciones telemáticas o electrónicas, el remitente podrá proceder a su presentación en la Oficina judicial el

${ }^{23}$ En el BOE 4 de noviembre se ha publicado la Ley 13/2009, de 3 de noviembre de Reforma de la Legislación Procesal para la Implantación de la Nueva Oficina Judicial. 
primer día hábil siguiente acompañando el justificante de dicha interrupción ${ }^{24}$.

\section{b) El traslado de copias}

El art. 273 de la LEC dispone que «de todo escrito y de cualquier documento que se aporte o presente en los juicios se acompañarán tantas copias literales cuantas sean las otras partes».

El traslado de las copias también podrá llevarse a cabo por medios electrónicos y con el resguardo acreditativo de su recepción. Un análisis de la incidencia del sistema Lexnet en este acto procesal obliga a realizar las siguientes puntualizaciones:

- De cada uno de los escritos electrónicos y de los documentos adjuntados electrónicamente se extraerán tantas copias como partes intervinientes haya, que llevarán igualmente incorporadas la firma electrónica del remitente.

- El traslado de las copias a las demás partes intervinientes se llevará a cabo por el Procurador de forma simultánea a la presentación del escrito o documento de que se trate por vía telemática (art. 274 LEC) en la Oficina judicial, sin que deba intervenir en tal caso el servicio de recepción de notificaciones al que alude el art. 28, apartado $3^{\circ} \mathrm{LEC}$, únicamente pensado para la recepción de notificaciones y copias de los escritos y documentos que sean presentados por los procuradores para su traslado a las demás partes intervinientes, pero no para la recepción de los escritos originales.

La excepción viene establecida para los supuestos de traslado de la demanda o de cualquier otro escrito del que dependa la primera comparecencia en juicio, en cuyo caso, con independencia de que las partes estén representadas por Procurador, será el Secretario judicial quien habrá de recibir los escritos y documentos con sus co-

${ }^{24}$ Sobre los problemas que plantea en otros ordenamientos determinar la fecha en la que se ha realizado el acto, véase JEULAND, E., «Arbitrage en ligne et procès virtuel : pour le principe de présence» Rév.huiss.just.dr.et proc., 2007, pp. 262 y sig., espéc. n. ${ }^{\circ} 13$, p. 263 : "La fecha considerada a veces es la fecha de envío (Bélgica), en algunos casos, como Rusia, es la fecha de recepción. En Holanda, el documento se considerara transmitido una vez que el mismo haya sido registrado por el sistema de registro de datos del tribunal, y recibido antes de las 12 am del último día del plazo. En caso de transmisión por el tribunal, la notificación se estimará realizada una vez que el tribunal haya entrado en contacto con un ordenador que no controle directamente». 
rrespondientes copias para trasladarlos a las demás partes (art. 273.3 LEC). Por la remisión que contiene el precepto a los art. 273 y 274 , esta actuación no podrá realizarse por medios telemáticos.

\section{c) El envío de comunicaciones}

Con respecto a los actos de comunicación a través de Internet, «las partes y los profesionales que intervengan en el proceso deberán comunicar a las Oficinas judiciales el hecho de disponer de los medios antes indicados y su dirección» (art. 162.1, II LEC) y «se constituirá en el Ministerio de Justicia un Registro accesible electrónicamente de los medios indicados y las direcciones correspondientes a los organismos públicos» (art. 162.1, III LEC).

Se ha previsto también, tras la modificación operada por la Ley $13 / 2009$, que si una vez constatada la correcta remisión del acto de comunicación por los mencionados medios técnicos, salvo los practicados a través de los servicios de notificaciones organizados por los Colegios de Procuradores, transcurrieran tres días sin que el destinatario haya accedido a su contenido, se considerará que la comunicación ha sido efectuada legalmente desplegando plenamente sus efectos, excepto que el destinatario justifique la falta de acceso al sistema de notificaciones durante este periodo.

Cuando el motivo alegado sea causas técnicas que persistan en el momento de ponerlas en conocimiento, el acto de comunicación se practicará mediante entraga de copia de la resolución.

No obstante, por economía procesal, en caso de producirse el acceso una vez transcurrido el plazo expuesto pero con anterioridad a la realización de la comunicación mediante entrega, se entenderá válidamente realizada la comunicación en la fecha que conste en el resguardo acreditativo de su recepción (art. 162.1, V LEC).

\section{III.2. La prueba documental electrónica}

La actividad procesal electrónica de las partes queda, sin embargo, modalizada cuando se trata de la prueba documental.

No cabe duda que la actual admisión de los actos de postulación de las partes por vía telemática va a suponer, en principio, una extraordinaria expansión de las pruebas aportadas en soporte electrónico como único modo de incorporarlas como anexo a la demanda 
presentada telemáticamente con firma digital reconocida (actual art. 267 LEC, redactado por la Ley 41/2007). Por eso, la Ley 56/2007, de 28 de diciembre, de Impulso a la Sociedad de la Información, dando nueva redacción a determinados apartados del art. 3 de la Ley, de 2003, de Regulación de la Firma Electrónica, dispone que el soporte en que se hallen los datos firmados electrónicamente sea admisible como prueba documental ${ }^{25}$.

Pero, formalmente, la nueva regulación de la prueba documental electrónica ha dejado algunos cabos sueltos.

\section{a) La presentación electrónica de documentos}

Perece ser que el legislador no confía plenamente en la suficiencia de lo aportado en soporte electrónico por cualquiera de las partes como prueba en el proceso. Del combinado de los artículos 267, 268 y 318 de la LEC (tras su reforma por la Ley 41/2007, de 7 de diciembre, sobre Regulación del Mercado Hipotecario) se deduce claramente que la regla general, en cuanto a la presentación electrónica de documentos se refiere, es que se lleve a cabo a través de una imagen digitalizada de la copia simple (tratándose de documentos públicos) o del original del documento obrante en papel (si son documentos privados), que habrá de ser incorporada a la demanda con firma electrónica reconocida.

Nuestro legislador ha ideado así un modo de convertir en electrónico, por la vía del scanner, un documento que, en realidad, no lo es, dando paso a una prueba documental mixta o pseudo-electrónica: de presentación electrónica pero con su soporte papel original, para el supuesto de que se impugne su autenticidad.

Algunas razones justifican que se vaya a usar y a consolidar progresivamente en nuestro ordenamiento esta técnica consistente en escanear documentos cuyo original obra en soporte papel para su transmisión electrónica.

Y es que los documentos originales electrónicos, cuando son de naturaleza pública, no tienen prácticamente cabida en nuestro ordenamiento, de ahí que no se pueda erradicar definitivamente el soporte

25 Señala ORTELLS con acierto que en teoría las posibilidades de regular la prueba documental electrónica con las que se encontraba nuestro legislador son dos: puede regular un medio de prueba específico, o puede encuadrar su introducción, con algún ajuste, en alguno de los medios tradicionalmente previstos. Incidencia de las nuevas tecnologías en el proceso jurisdiccional..., cit., pág. 659. 
papel para esta modalidad de prueba. La legislación notarial constituye un ejemplo interesante ${ }^{26}$.

El documento notarial electrónico - por expresa prescripción le$\mathrm{gal}^{27}$ - es siempre una copia o reproducción telemática del documento original elaborado y conservado en papel, hasta que los avances tecnológicos (dice una disposición transitoria ${ }^{28}$ ) permitan sustituirlo por un soporte electrónico. Por tanto, no hay matrices electrónicas sino sólo copias electrónicas de escrituras públicas que, por razones de seguridad, para mayor garantía de los ciudadanos, sólo pueden encontrarse a disposición de otro Notario o funcionario público (judicial, administrativo o registral) ${ }^{29}$. A los particulares interesados en un documento notarial sólo cabe remitir por vía telemática, todo lo más, una copia simple, sin firma digital reconocida ${ }^{30}$, por lo que dichos particulares no podrán ser nunca destinatarios ni estar en posesión de documentos notariales electrónicos.

Algo parecido ocurre con los libros del registro de la propiedad. La reforma introducida por la Ley 24/2005 (antes citada), dando nueva redacción al art. 238 de la Ley Hipotecaria ${ }^{31}$, dispone que los libros del registro deben llevarse por medios electrónicos. Pudiera pensarse que el asiento registral es, en cierto modo, también una copia o reproducción de otro documento, el título inscribible que se presenta a

${ }^{26}$ Vid. MADRIDEJOS FERNÁNDEZ, en op. cit., págs. 70 y ss.

${ }^{27}$ Según la Disposición Transitoria Undécima de la Ley Notarial (adicionada por el art. 115 de la Ley 24/2001, de 27 de diciembre, de Medidas Fiscales, Administrativas y de Orden Social), «hasta que los avances tecnológicos hagan posible que la matriz $\mathrm{u}$ original del documento notarial se autorice o intervenga y se conserve en soporte electrónico, la regulación del documento público electrónico contenida en este artículo se entenderá aplicable exclusivamente a las copias de la matrices de escrituras y actas, así como, en su caso, a la reproducción de las pólizas intervenidas».

${ }_{28}$ Véase mi trabajo, en MIRA ROS, C., «La nueva regulación notarial de los títulos ejecutivos», Diario La Ley, N. ${ }^{\circ}$ 6931, 2008., pág. 2.

${ }_{29}$ Conforme al actual art. 224.4 del Reglamento Notarial, las copias autorizadas electrónicas «sólo podrán expedirse para su remisión a otro Notario, a un registrador o a cualquier órgano judicial o de las Administraciones Públicas, siempre dentro del ámbito de su respectiva competencia y por razón de su oficio».

${ }^{30}$ Conforme al art. 224, in fine, del Reglamento Notarial, «en lo relativo a las copias simples, éstas podrán remitirse a cualquier interesado...».

$31 \mathrm{El}$ art. 28 de la Ley 24/2005, de 18 de noviembre, da nueva redacción al art. 238 LH, a cuyo tenor, «el Registro de la Propiedad se llevará en libros foliados y visados judicialmente. Los libros de los Registros de la Propiedad, Mercantiles y de Bienes Muebles deberán llevarse por medios informáticos que permitan en todo momento el acceso telemático a su contenido. El Registro dispondrá de un sistema de sellado temporal que dejará constancia del momento en que el soporte papel se trasladó a soporte informático. En caso de destrucción de los libros, se sustituirán con arreglo a las Leyes de 15 de agosto de 1873 y 5 de julio de $1938 »$. 
inscripción. Sin embargo, en otros apartados del mismo art. $238 \mathrm{LH}$, se sigue hablando de libros foliados y sellados, es decir, libros en papel, de modo que los asientos registrales se siguen extendiendo en libros en papel y no en formato electrónico.

En el ámbito de la Administración pública, conforme a la nueva Ley 11/2007, de 22 de junio, sobre el Acceso Electrónico de los Ciudadanos a los Servicios Públicos, cabe, por el contrario, el documento administrativo electrónico original, reproducible, a su vez, electrónicamente (art. 29 y 30). Es decir, el original del documento administrativo no tiene ya que constar en papel, puede ser electrónico. Por eso, la reforma de la LEC por la Ley 41/2007, de 7 de diciembre, sobre Regulación del Mercado Hipotecario, a la hora de regular la producción de la prueba por documentos públicos, admite expresamente la aportación al proceso en original o por copia fehaciente del documento electrónico (art. 318 LEC) en abierta contradicción con el art. 267 de la LEC que, al regular la forma de presentación de los documentos públicos, omite toda referencia a la aportación original de los documentos públicos electrónicos..

Los documentos electrónicos privados no parece, por el contrario, que puedan aportarse al proceso en soporte original, pues la Ley nuevamente parece silenciar su existencia al remitirse a la posible presentación de documentos electrónicos en todo caso a través de las imágenes digitalizadas de los originales, copias fehacientes o copias simples de los mismos (art. 268 LEC).

En cualquier caso, el proceso de digitalización puede generar inseguridad, como consecuencia de la facilidad para falsificar el contenido del documento escaneado. Cabe, pues, esperar, tal y como ya se ha abordado en el ámbito de la facturación electrónica, la regulación de un sistema de digitalización certificado, que permita convertir la imagen contenida en un documento en papel en una imagen digital codificada, fiel e íntegra respecto del original. Será, entonces, necesario integrar en el software de digitalización un sistema de firma digital y utilizar, además, un certificado de firma electrónica a cargo de quien desarrolla el sistema de digitalización.

\section{b) La impugnación de los documentos electrónicos}

En el proceso civil, la impugnación del documento público electrónico no presenta ninguna anomalía con respecto al documento público extendido en soporte papel: se va a resolver, conforme al artí- 
culo 320 LEC, por el cotejo de la copia digital con el documento original en papel a que corresponda - obrante en el protocolo o archivo del funcionario correspondiente-, cuya intelección (a diferencia de lo que ocurre con el disco duro de un ordenador) va a ser objeto de una comprensión directa por el juez, sin mediación de otras personas (testigos ni peritos o expertos en informática), cobrando la atendibilidad de ese medio de prueba verdaderamente sentido de prueba documental, pues lo que distingue al documento de otros medios de prueba es, precisamente, su aptitud como objeto de inmediata comprensión directa y autónoma por el juzgador, sin depender de la opinión o posible influencia de otros sujetos.

A diferencia de lo que ocurre con el documento público electrónico, el documento privado electrónico, independientemente de que tenga o no firma electrónica avanzada o reconocida, si se discute su admisión como medio de prueba en el proceso, impugnándose su autenticidad o, en su caso, la exactitud o regularidad de la certificación que atestigua el reconocimiento de la firma, va a operar, de acuerdo con el apartado 8 del art. 3 de la Ley de Firma Electrónica (La ley 56/2007, de 28 de diciembre, de Medidas de Impulso de la Sociedad de la Información) $)^{32}$, al que se remite el art. 326 de la LEC, como una compleja prueba pericial o testifical, sujetándose su eficacia, en cuanto a su valoración, a la apreciación del juez con arreglo a su sana crítica.

En el actual estadio histórico de evolución de las modernas tecnologías, la prohibición de documentos públicos electrónicos que

32 Conforme con dicho precepto:

(...) Si se impugnare la autenticidad de la firma electrónica reconocida con la que se hayan firmado los datos incorporados al documento electrónico se procederá a comprobar que se trata de una firma electrónica avanzada basada en un certificado reconocido, que cumple todos los requisitos y condiciones establecidos en esta Ley para este tipo de certificados, así como que la firma se ha generado mediante un dispositivo seguro de creación de firma electrónica.

La carga de realizar las citadas comprobaciones corresponderá a quien haya presentado el documento electrónico firmado con firma electrónica reconocida. Si dichas comprobaciones obtienen un resultado positivo, se presumirá la autenticidad de la firma electrónica reconocida con la que se haya firmado dicho documento electrónico siendo las costas, gastos y derechos que origine la comprobación exclusivamente a cargo de quien hubiese formulado la impugnación. Si, a juicio del tribunal, la impugnación hubiese sido temeraria, podrá imponerle, además, una multa de 120 a 600 euros.

Si se impugna la autenticidad de la firma electrónica avanzada, con la que se hayan firmado los datos incorporados al documento electrónico, se estará a lo establecido en el apartado 2 del artículo 326 de la Ley de Enjuiciamiento Civil. 
sean copia de otros documentos públicos electrónicos (como ocurre con los propios actos jurisdiccionales del juez, cuyo original siempre ha de documentarse en papel, en materia de documentos notariales, todavía con los libros del registro de la propiedad probablemente, y con las resoluciones administrativas en general) quizá se explique como una medida de política procesal, consistente en la voluntad del legislador de imponer en ciertos supuestos de especial trascendencia económica, social o jurídica, por razón de asegurar una mayor tutela judicial efectiva, la necesidad de una prueba documental que, en caso de contienda judicial, quede sujeta en último término a la capacidad intelectiva directa y autónoma del juzgador, con plena independencia, no condicionada por testimonios ni pericias de terceros ${ }^{33}$.

\section{III.3. La utilización de los medios técnicos de filmación y reproducción de la imagen y el sonido}

Después de varias decisiones judiciales acordando este método y los reproches formulados a su legalidad y constitucionalidad, el legislador, a través de la Disposición Adicional única de la Ley Orgánica 13/2003, de 24 de octubre, de Reforma de la Ley de Enjuiciamiento Criminal en materia de prisión provisional, introduce un tercer apartado en el art. 229 de la LOPJ, dejando definitivamente zanjada la cuestión en torno a la cobertura legal del uso de la videoconferencia en el proceso civil ${ }^{34}$.

Ahora, el nuevo precepto establece que «las actuaciones orales que requieran inmediación procesal podrán realizarse a través de videoconferencia u otro sistema similar que permita la comunicación bidireccional y simultánea de la imagen y el sonido y la interacción visual, auditiva y verbal entre dos personas o grupos de personas geográficamente distantes, asegurando en todo caso la posibilidad de

33 Véase la comunicación presentada por mí en el Coloquio de la Asociación Internacional de Derecho Procesal celebrado en Gandía (Valencia) del 6 al 8 de noviembre de 2008 y que ha sido publicada con el título «La prueba documental electrónica: algunas concesiones a la seguridad jurídico preventiva», en el Tomo II de la obra colectiva Oralidad y escritura en un proceso civil eficiente (a cargo del profesor Ortells Ramos y del profesor Federico Carpi), Universidad de Valencia, 2008.

${ }^{34}$ En España la técnica de la videoconferencia ha sido prevista en sucesivas disposiciones: los arts. 229 y 230 de la LOPJ y los arts. 306, 325 y 731 bis de la LECrim. La LOPJ contiene una previsión genérica en su artículo 230, bajo el cual se entendió posible la utilización de estas técnicas. Posteriormente la Ley Orgánica 13/2003, del 24 de octubre, agregó el numeral $3^{\circ}$ al art. 229 de la Ley Orgánica del Poder Judicial. 
contradicción de las partes y la salvaguarda del derecho de defensa, cuando así lo acuerde el Juez o Tribunal».

En estos casos, el Secretario Judicial del Juzgado o Tribunal que haya acordado la medida acreditará desde la propia sede judicial la identidad de las personas que intervengan a través de la videoconferencia, «mediante la previa remisión o la exhibición directa de documentación, por conocimiento personal o por cualquier otro medio procesal idóneo».

Asimismo, la cobertura legal se encuentra reforzada en el artículo 230 de la Ley Orgánica del Poder Judicial (modificada por L. O. 16/94, de 8 de Noviembre) que autoriza la utilización de «cualesquiera medios técnicos, electrónicos e informáticos».

La normativa transcrita establece cuales son las condiciones que se exigen al sistema de videoconferencia o similar para que pueda producirse una interacción visual, auditiva y verbal entre las personas o grupos de personas intervinientes en la actuación procesal de que se trate, garantizando el principio de audiencia y contradicción ${ }^{35}$ y asegurando las exigencias derivadas de la fe pública judicial ${ }^{36}$. Pero nada se ha establecido en la LEC, a diferencia de lo regulado en el proceso penal ${ }^{37}$, sobre cuál es el régimen al que queda sometida su adopción.

35 En opinión de GONZÁLEZ GARCÍA, J. M., «La videoconferencia como instrumento para la agilización de la justicia penal: nota sobre el modelo español», Problemas actuales del Proceso Iberoamericano, Volumen II, CEDMA, Vol. II, Málaga, 2006, p. 437, de la redacción actual del artículo 229.3 de la Ley Orgánica del Poder Judicial se deduce la voluntad del legislador español de conjurar algunas de las más importantes reticencias que plantea la introducción de la videoconferencia en el proceso permitiéndola incluso para el orden penal. En opinión de VELASCO NUÑEZ, E., «Videoconferencia y Administración de Justicia», La Ley, núm. 5630, de 10 de octubre de 2002 , p. 2, esta supone una de las mayores utilidades prácticas de la videoconferencia, superándose, en el caso de las solicitudes de auxilio judicial, tanto interno como internacional, la rigidez del interrogatorio por escrito.

36 Opina BUJOSA VADELL, L. M., en «Prueba de testigos y cooperación judicial internacional en materia penal», en La Ley, núm. 5627, de 7 de octubre de 2002, pp. 18 , que la presencia del Secretario judicial en el lugar de la declaración, que fije en el acta la identidad del sujeto declarante, la autenticidad de la declaración y los detalles y condiciones en que se ha llevado a cabo la videoconferencia, constatando las posibles interferencias o defectos de recepción, es uno de los estándares que garantizan una mínima calidad de la contradicción, de la inmediación y de la publicidad que se produce con la aplicación de estos medios probatorios. De la misma forma se destaca la importancia de su presencia en orden a garantizar que se den todas las garantías técnicas que impidan la manipulación de la emisión.

37 El legislador por Ley Orgánica 13/2003, introduce en la Ley de Enjuiciamiento Criminal el artículo 731 bis, cuyo texto conviene transcribir: «El Tribunal de oficio o instancia de parte, por razones de utilidad, seguridad o de orden público, así como en 
Sabemos, por su incidencia sobre los principios de oralidad, inmediación, contradicción y publicidad, que la declaración a través de videoconferencia ha de tratarse de una medida de carácter excepcional, pero no cabe denegar su utilización alegando la impertinencia o inutilidad del medio probatorio al que sirve instrumentalmente. Se trata de dos decisiones judiciales, sobre la pertinencia y utilidad del medio probatorio, una y sobre la oportunidad o proporcionalidad del modo de practicarlo, la otra, cuya confusión puede generar una vulneración del derecho fundamental a la utilización de las pruebas que sean pertinentes, ocasionando indefensión ${ }^{38}$.

aquellos supuestos en los que la comparecencia de quien haya de intervenir en cualquier tipo de procedimiento penal como imputado, testigo, perito o en otra condición resulte gravosa o perjudicial, podrá acordar que su actuación se realice a través de videoconferencia u otro sistema similar que permita la comunicación bidireccional y simultánea de la imagen y el sonido, de acuerdo con lo dispuesto en el apartado 3 del artículo 229 de la Ley Orgánica del Poder Judicial».

38 Véase la Sentencia del TC, Sala Segunda, Sentencia 82/2006, de 13 Mar. de 2006, rec. 5634/2004. En ella se exponen los argumentos en torno a la vulneración del derecho a la utilización de los medios de prueba.

Ante la negativa de la Sala de la Audiencia Nacional a acordar la práctica del interrogatorio del extraditado a través de la videoconferencia, para decidir sobre la ampliación del objeto de la extradición. «3. El demandante de amparo considera, en primer término, que ha resultado vulnerado su derecho a utilizar los medios de prueba pertinentes para la defensa (art. 24.2 CE) por la negativa de la Sección Primera de la Sala de lo Penal de la Audiencia Nacional a la solicitud de prestar declaración en el acto de la vista mediante videoconferencia, pese a que el art. 14 de la Ley 4/1985, de 21 de marzo, de Extradición Pasiva (LEP), establece en dicho acto la confesión del extradendus, así como a que se enviase una comisión rogatoria a las autoridades de la República del Perú para que remitieran el expediente completo de la extradición que contra él se ha seguido en el Reino Unido.

De acuerdo con la jurisprudencia de este Tribunal, sintetizada, entre otras, en la STC 1/2004, de 14 de enero (LA LEY 11122/2004) (FJ 2), para que pueda apreciarse la vulneración del derecho a la prueba se exige, en primer lugar, que el recurrente haya instado a los órganos judiciales la práctica de una actividad probatoria, respetando las previsiones legales al respecto. En segundo lugar, que los órganos judiciales hayan rechazado su práctica sin motivación, con una motivación incongruente, arbitraria o irrazonable, de una manera tardía o que, habiendo admitido la prueba, finalmente no hubiera podido practicarse ésta por causas imputables al propio órgano judicial. En tercer lugar, que la actividad probatoria que no fue admitida o practicada hubiera podido tener una influencia decisiva en la resolución del pleito, generando indefensión al actor. Y, por último, que el recurrente en la demanda de amparo alegue y fundamente los anteriores extremos.

El punto de partida en el examen de la vulneración del derecho a la prueba ha de ser el reconocimiento de que el art. 24.2 CE establece el derecho a utilizar los medios de prueba pertinentes para la defensa, lo que implica, como hemos reiterado, que este derecho garantiza a las partes la posibilidad de impulsar una actividad probatoria acorde con sus intereses. Ahora bien, la propia formulación del art. 24.2 CE, que se refiere a la utilización de los medios de prueba «pertinentes», implica que su reconoci- 


\section{En cualquier caso, en defecto de una concreta regulación sobre el uso de la videoconferencia en el proceso civil, será necesario atender a estas dos consideraciones:}

miento no ampara un hipotético derecho a llevar a cabo una actividad probatoria ilimitada, en virtud de la cual las partes estarían facultadas para exigir cualesquiera pruebas que tuvieran a bien proponer, sino que atribuye sólo el derecho a la admisión y práctica de las que sean pertinentes, entendiendo por tales aquellas pruebas que tengan una relación con el thema decidendi, ya que, como señaló muy tempranamente este Tribunal, la opinión contraria, no sólo iría contra el tenor literal del art. 24.2 CE, sino que conduciría a que, a través de propuestas de pruebas numerosas e inútiles, se pudiese alargar indebidamente el proceso o se discutiesen cuestiones ajenas a su finalidad.

De otra parte, es a los órganos judiciales a quienes compete la interpretación de las normas legales aplicables sobre la admisión y práctica de los medios de prueba; ellos son quienes han de pronunciarse sobre su admisibilidad motivadamente sin incurrir en incongruencia, irrazonabilidad o arbitrariedad, y, en su caso, la falta de práctica de los medios de prueba admitidos no les ha de ser imputable. Igualmente el rechazo motivado de los medios de prueba ha de producirse en el momento procesal oportuno.

Por último el alcance de esta garantía constitucional exige que, para apreciar su vulneración, quede acreditada la existencia de una indefensión constitucionalmente relevante; ello se traduce en la necesidad de demostrar que la actividad probatoria que no fue admitida o practicada era decisiva en términos de defensa, esto es, que hubiera podido tener una influencia decisiva en la resolución del pleito, al ser susceptible de alterar el fallo en favor del recurrente. Teniendo en cuenta que la carga de la argumentación recae sobre los solicitantes de amparo, corresponde al recurrente alegar y fundamentar adecuadamente que la prueba en cuestión resulta determinante en términos de defensa, sin que la verificación de tal extremo pueda ser emprendida por este Tribunal mediante un examen de oficio de las circunstancias concurrentes en cada caso concreto. De ese modo el recurrente ha de razonar en esta sede en un doble sentido. Por un lado, respecto de la relación entre los hechos que se quisieron y no se pudieron probar y las pruebas inadmitidas; de otro, argumentando que la resolución final del proceso judicial podría haberle sido favorable de haberse aceptado y practicado la prueba objeto de controversia, ya que sólo en tal caso, comprobado que el fallo pudo, acaso, haber sido otro si la prueba se hubiera admitido, podrá apreciarse también el menoscabo efectivo del derecho de quien, por este motivo, busca amparo.

4. En este caso, por lo que se refiere a la solicitud de que durante el acto de la vista se recibiese confesión al demandante de amparo por videoconferencia, pues se encontraba en la República del Perú al haber sido entregado a este país por las autoridades españolas con su consentimiento en el expediente de extradición núm. 73/2003, la Sección Primera de la Sala de lo Penal de la Audiencia Nacional, por Auto de 30 de diciembre de 2003, declaró no haber lugar a aquella solicitud por constar «suficientemente en las actuaciones, en relación con el art. 13 del Convenio Hispano-Peruano sobre extradición, la negativa de $\mathrm{O}$. a la ampliación de extradición y a expresar ante las Autoridades peruanas su consentimiento o no al respecto»; porque «una declaración de O. como prueba, en relación con el art. 14 de la Ley española de Extradición Pasiva, no se estima necesaria, atendidas las actuaciones ya practicadas, incluidos los escritos remitidos por el reclamado»; y, en fin, porque «las alegaciones que puedan realizarse sobre la improcedencia de la ampliación corresponde efectuarlas a la Defensa técnica». 
La práctica de la prueba a través de la videoconferencia sustituye en cierta medida al sistema de auxilio judicial, constituyendo un tercer eslabón en la cadena de instrumentos orientados a posibilitar la práctica excepcional de determinados medios probatorios fuera de la sede judicial. Por esta razón, serán las propias normas reguladoras del exhorto (art. 169 y ss. de la LEC) y también aquéllas relativas a la constitución del Tribunal dentro o fuera del territorio de su circunscripción (art. 129.3 de la LEC), las que determinen cuándo se podrá instar la práctica de una declaración de parte, testifical o pericial (ratificación del informe) a través de la videoconferencia y cuáles son los criterios que rigen su admisión (distancia, dificultad de desplazamiento, circunstancias personales de la parte, testigo o perito que hagan imposible o muy gravosa la comparecencia personal).

Y, puesto que se trata de una técnica de prueba que puede limitar principios constitucionalmente protegidos, cuya infracción determina la nulidad de actuaciones, esta decisión sobre su admisión debiera adoptar la forma de auto, previa audiencia de las partes personadas, de modo similar a cuanto se regula por la LEC para la celebración a puerta cerrada de actuaciones que normalmente se practican en audiencia pública (art. 138 LEC).

\section{III.4. La documentación electrónica de los actos procesales: la grabación en soporte audiovisual de los actos orales}

El impacto de las nuevas tecnologías ha alcanzado también, como no podía ser de otro modo, a la mecánica de la documentación de los actos procesales.

El levantamiento del acta por el Secretario Judicial, como modo de dejar constancia fehaciente del desarrollo de las comparecencias y vistas orales y de cuanto en ellas había acontecido, se ha visto

Por su parte, en relación con dicha negativa, el Pleno de la Sala de lo Penal de la Audiencia Nacional, en su Auto núm. 88/2004, de 20 de julio, argumenta al respecto que en este caso se trata de una demanda de ampliación extradicional, «de tal forma que el reclamado ya ha sido entregado al Estado de la República del Perú, después de acceder a la entrega extradicional con un primer procedimiento instado por el Estado peruano. Ya realizada la entrega, difícilmente va a recibírsele declaración en el seno del proceso extradicional español. Como sucede en todos los supuestos de ampliación extradicional. De otro lado, consta tanto en el Tribunal de Instancia como a este propio Pleno la voluntad contraria de entrega a la ampliación extradicional (...) puesta de manifiesto a lo largo de la tramitación de la causa» (Razonamiento Jurídico Primero). 
sustancialmente transformado por un sistema de documentación biforme, que combina a la perfección los medios audiovisuales o, si no fuera posible, los medios de recogida y plasmación del sonido exclusivamente con la redacción por el Secretario de un acta sucinta.

La obligación contenida en el art. 147 de la LEC, de registrar en un soporte apto para la grabación y reproducción del sonido y de la imagen las actuaciones orales que se desarrollan en las vistas y comparecencias, es absolutamente coherente con la naturaleza de nuestro recurso de apelación, configurado como una «revisio prioris instancia», en la que el órgano «ad quem» tiene plena competencia para revisar todo lo actuado por el Juzgador de Instancia, tanto en lo que afecta a los hechos («quastio facti») como en lo relativo a las cuestiones jurídicas oportunamente deducidas por las partes («quastio iuris»), pudiendo no sólo revocar, adicionar, suplir y enmendar las sentencias de los inferiores, sino dictar respecto de todas las cuestiones debatidas el pronunciamiento que proceda ${ }^{39}$.

La digitalización de los autos a través de este sistema facilita además una mejor valoración de la prueba, tanto en primera instancia como en la apelación, asegurando que este conocimiento integro en segunda instancia se lleve a cabo bajo el cumplimiento de los principios procesales de inmediación, contradicción, prohibición de la «mutatio libelli» y garantiza igualmente el derecho de defensa, al suministrar a las partes, con el visionado de las grabaciones, un instrumento para fundamentar adecuadamente sus alegaciones y probar sus derechos e intereses legítimos, sin que en ningún caso se produzca indefensión ${ }^{40}$.

39 Extracto de las sentencias AP Asturias n. ${ }^{\circ}$ 251/2006, de 9 de mayo; SAP Ciudad Real n. ${ }^{\circ}$ 88/2006 (secc. 2. ${ }^{\text {a }}$ ), de 4 de abril; SAP Baleares n. ${ }^{\circ} 127 / 2006$, de 21 de marzo y SAP Huelva n. ${ }^{\circ}$ 139/2007 (secc. 1. ${ }^{\text {a) }}$, de 24 de octubre, entre las más recientes. Recoge dicha jurisprudencia y la extracta del mismo modo GARCÍA-LUBÉN BARTHE, P; "Problemas que plantean los defectos de grabación de la vista en los juicios civiles», Oralidad y escritura en un proceso civil eficiente (a cargo de Federico Carpi y Manuel Ortells), Universidad de Valencia, 2008, pág. 67 y ss.

${ }^{40} \mathrm{La}$ importancia de la grabación a efectos de un futuro pronunciamiento judicial es puesta de manifiesto por MAGRO SERVET, para quien «una de las ventajas de la grabación en video de los juicios civiles es, precisamente, la que la Audiencia Provincial va a poder valorar debidamente y con la misma inmediación del Juez Civil la prueba ante el primero practicada, habida cuenta de que la posibilidad de poder visionar la prueba eleva la inmediación de la primera instancia a la segunda». "Comentario al artículo 147 de la LEC», El Proceso Civil Práctico (Dirigido por GIMENO SENDRA), Madrid, 2001, págs. 2 a 139. 


\section{a) La subsistencia del acta escrita}

Y a remolque de este nuevo documento electrónico el acta escrita del secretario judicial, en el orden físico, ha comenzado a perder peso, pues aunque resulta difícil dar una lectura coherente a los distintos párrafos del art. 146 de la LEC, lo que sí no cabe pretender es que la Ley propugna un imposible lógico: la documentación de un acto procesal en dos soportes, en papel —o ahora también extendida por procedimientos informáticos-, y el soporte apto para la grabación y reproducción del sonido y de la imagen. No se entendería esta dualidad ni siquiera por exigencias de la fe pública judicial, pues en el momento en que se diera cualquier divergencia entre ambos sistemas (defecto en la grabación, error, fallo) habría que decidir cuál es el acta auténtica que servirá de base para la resolución de las cuestiones procesales planteadas por las partes.

La constancia absoluta por escrito de las actuaciones orales pasa entonces a tener solo un valor auxiliar, como una regla aplicable en el supuesto de que, previa comprobación por el Secretario Judicial, los medios de grabación y reproducción del sonido y de la imagen no vayan a funcionar en principio correctamente (art. 187.2 de la LEC). En otro caso, bastará, dice la LEC, con consignar «junto con los datos relativos al tiempo, y al lugar, el número y clase de procedimiento, al tiempo de duración, asistentes al acto, peticiones y propuestas de las partes, en caso de proposición de pruebas, pertinencia y orden en la práctica de las mismas, las resoluciones que adopte el Tribunal, así como las circunstancias e incidencias que no pudieran constar en soporte electrónico». (art. 146.2,3 apartado de la LEC, tras la nueva redacción otorgada por la Ley 13/2009).

Pero la subsistencia de este acta sucinta es, sin embargo, un anacronismo que solo denota, como en tantos otros avances tecnológicos, una cierta reminiscencia de tiempos pasados, igual que, cuando se inventó la bombilla eléctrica, las lámparas se diseñaban imitando todavía las antiguas velas.

Su insuficiencia para acreditar la práctica de los actos procesales orales que se realizan en la vista o comparecencia ha conducido a que las Audiencias Provinciales declaren la nulidad del juicio ante la eventual inexistencia, pérdida o deterioro de las grabaciones originales que documentan la existencia del acto ${ }^{41}$. Queda patente en la

${ }^{41}$ Ver las citas y transcripciones jurisprudenciales que se encuentran en ADAN DOMENECH, F., «Problemática judicial de la documentación de las actuaciones 
jurisprudencia que, si falla el soporte audiovisual, un acta restringida no permite reconstruir las alegaciones efectuadas en las vistas o comparecencias por los letrados de las partes personadas en el proceso, ni tampoco permite dejar constancia del resultado de la prueba practicada. Existiría entonces un déficit de documentación que afectaría al derecho a los recursos y, a la postre, a la función revisora del órgano judicial de segunda instancia, ocasionando todo ello indefensión.

Llegados a este punto sí que parece entonces pertinente la pregunta de si, con esta «miniaturización» del acta, solo se altera la mecánica de la documentación, o si, por el contrario, es solo el primer paso de una revisión más profunda que afecta a la propia subsistencia de esta función del Secretario Judicial.

\section{b) La firma electrónica del secretario judicial}

Se ha pensado que con la implantación de las nuevas tecnologías en un proceso fundamentalmente oral el Secretario Judicial se convierte en una especie de "convidado de piedra» (como ha apuntado MORENO CATENA) ${ }^{42}$, resultando más importante su función de «custodia de las cintas, discos o dispositivos en los que la grabación se hubiese efectuado» (prevista en el art. 147 LEC) que su propia función testimonial en los autos.

Por eso no es de extrañar que el siguiente paso del legislador se haya encaminado a prescindir incluso de la obligatoria presencia del Secretario Judicial en las vistas cuando el documento electrónico que contenga la grabación incorpore su firma electrónica reconoci$\mathrm{da}^{43}$.

Esta idea de una presencia virtual del Secretario Judicial fue el planteamiento inicial del Real Decreto 1608/2005, de 30 de diciembre, por el que se aprueba el Reglamento Orgánico del Cuerpo de Secre-

procesales orales», Oralidad y escritura en un proceso civil eficiente(Carpi y Ortells), Universidad de Valencia, 2008, Tomo II, pág. 42 y ss. Los matices de esta doctrina jurisprudencial se pueden encontrar también en ARANGUENA, C., "Comentarios al artículo 147 de la LEC», Comentarios a la nueva Ley de Enjuiciamiento Civil, (Dirigidos por LORCA NAVARRETE), t. III, Valladolid, pág. 966.

42 «Del manuscrito a la informática (revisión del papel del Secretario judicial en la sociedad de la información)», en Libro homenaje al profesor Dr. D. ${ }^{\circ}$ Eduardo Font Serra, Madrid, 2004, vol. I, Ministerio de Justicia-Centro de Estudios Jurídicos, pág. 479.

${ }_{43}$ El artículo 147, apartado segundo, de la LEC, tras la nueva redacción ofrecida por la Ley 13/2009. 
tarios Judiciales ${ }^{44}$ y es también la filosofía que inspiró el Proyecto de 23 de diciembre de 2008 de Reforma de la Legislación Procesal para la Implantación de la Nueva Oficina Judicial ${ }^{45}$. La técnica normativa empleada por el inicial Proyecto pecaba, sin embargo, de grave ambigüedad, pues si el documento electrónico que contenga la grabación, siempre que incorpore la firma electrónica reconocida del secretario judicial, constituye el acta a todos los efectos, ¿qué sentido tiene entonces reformar el artículo 225 de la LEC, introduciendo como nueva causa de nulidad de pleno derecho la celebración de vistas sin la presencia del Secretario Judicial? ${ }^{46}$.

${ }^{44}$ El Real Decreto 1608/2005, de 30 de diciembre, por el que se aprueba el Reglamento Orgánico del Cuerpo de Secretarios Judiciales ya había regulado en su art. 5 que, como titulares de la fe pública judicial y en el ejercicio de esta función "Dejarán constancia fehaciente de la realización de actos procesales en el Tribunal o ante éste y de la producción de hechos con trascendencia procesal mediante las oportunas actas y diligencias. Cuando se utilicen medios técnicos de grabación o reproducción, garantizarán la autenticidad e integridad de lo grabado o reproducido.

Tal garantía se prestará preferentemente mediante la incorporación de firma electrónica reconocida, de la que el Ministerio de Justicia o las Comunidades Autónomas que hayan recibido los traspasos de medios personales al servicio de la Administración de Justicia dotarán a todos los Secretarios Judiciales, utilizando para ello los medios técnicos que ofrezcan el nivel de máxima fiabilidad reconocida, en consonancia con la legalidad vigente en materia de firma electrónica. El Ministerio de Justicia regulará los supuestos y modos en que se debe hacer uso por los Secretarios Judiciales de la firma electrónica».

45 El artículo 147 de la LEC, tras su modificación por el Proyecto de reformas procesales para la nueva implantación de la oficina judicial (23 de diciembre de 2008) hubiera quedado redactado como sigue:

«Artículo 147. Documentación de las actuaciones mediante sistemas de grabación y reproducción de la imagen y el sonido. Las actuaciones orales en vistas, audiencias y comparecencias celebradas ante el tribunal, se registrarán en soporte apto para la grabación y reproducción del sonido y la imagen. Siempre que se cuente con los medios tecnológicos necesarios, el Secretario Judicial garantizará la autenticidad e integridad de lo grabado mediante la utilización de la firma electrónica reconocida $u$ otro sistema de seguridad que conforme a la ley ofrezca tales garantías. En este último caso, la celebración del acto se llevará a cabo sin la presencia en la sala del Secretario Judicial. El secretario judicial deberá custodiar el documento electrónico que sirva de soporte a la grabación. Las partes podrán pedir, a su costa, copia de las grabaciones originales».

${ }_{46}$ En el artículo ciento treinta y tres del Proyecto para la creación de la nueva oficina judicial se daba nueva redacción al art. 225 de la LEC, que queda redactado como sigue:

"Artículo 225. Nulidad de pleno derecho.

Los actos procesales serán nulos de pleno derecho en los casos siguientes:

1. ${ }^{\circ}$ Cuando se produzcan por o ante tribunal con falta de jurisdicción o de competencia objetiva o funcional.

2. ${ }^{\circ}$ Cuando se realicen bajo violencia o intimidación.

3. ${ }^{\circ}$ Cuando se prescinda de normas esenciales del procedimiento, siempre que, por esa causa, haya podido producirse indefensión.

4. ${ }^{\circ}$ Cuando se realicen sin intervención de Abogado, en los casos en que la ley la establezca como obligatoria. 
Quizá nuestro legislador solo parcialmente se había percatado de que la celebración del acto sin la presencia del Secretario Judicial en la Sala obstaculiza enormemente las funciones de ordenación e impulso del proceso, que el propio Proyecto seguía encomendando a los Secretarios Judiciales incluso de forma aumentada. Difícilmente podría dictarse - en forma oral, decía entonces el Proyecto ${ }^{47}$ - una diligencia de ordenación para dar curso formal a los autos un Secretario que se ausentara de la Sala en la celebración de una vista, audiencia o comparecencia. Con la novedosa apuesta expansiva de las funciones del Secretario Judicial en el Proyecto frustrado, nuestro legislador se había olvidado de que la implantación de la oralidad en el proceso civil y el fomento de las nuevas tecnologías dejan sin sentido igualmente la conservación en manos de este fedatario judicial de la potestad ordenatoria del proceso, pensada fundamentalmente para los procesos regidos por el principio de escritura.

Pero, con fecha 4 de noviembre de 2009 se ha publicado en el BOE la Ley 13/2009, de Reforma de la Legislación Procesal para la Implantación de la Nueva Oficina Judicial.

Ahora, el nuevo artículo 147 de la LEC prevé nuevamente la utilización de la firma electrónica reconocida u otro sistema de seguridad en la grabación de las vistas, audiencias y comparecencias, de forma que quede garantizada la autenticidad e integridad de lo grabado. Y también se establece que el documento electrónico que contenga la grabación, siempre que incorpore la firma electrónica reconocida del Secretario judicial, constituirá el acta a todos los efectos. Pero, a diferencia de lo establecido en el Proyecto anterior, será necesaria la presencia del Secretario Judicial en la sala si lo han solicitado las partes con anterioridad o si excepcionalmente lo considera éste oportuno atendiendo, entre otras razones, a la complejidad del asunto o al

5. Cuando se celebren vistas sin la preceptiva intervención del secretario judicial.

6. Cuando se resolvieran mediante diligencias de ordenación o decreto cuestiones que, conforme a la ley, hayan de ser resueltas por medio de providencia, auto o sentencia.

7. ${ }^{\circ}$ En los demás casos en que esta ley así lo establezca».

47 Conforme a la redacción que el proyecto otorga al art. 210 de la LEC:

«1. Salvo que la ley permita diferir el pronunciamiento, las resoluciones que deban dictarse en la celebración de una vista, audiencia o comparecencia ante el tribunal o secretario judicial se pronunciarán oralmente en el mismo acto, documentándose éste con expresión del fallo y motivación sucinta de aquellas resoluciones».

"2. Pronunciada oralmente una resolución, si todas las personas que fueren parte en el proceso estuvieren presentes en el acto, por sí o debidamente representadas, y expresaren su decisión de no recurrir, se declarará, en el mismo acto, la firmeza de la resolución.

Fuera de este caso, el plazo para recurrir comenzará a contar desde la notificación de la resolución debidamente redactada». 
número y naturaleza de las pruebas que deban practicarse. En tales casos, el Secretario Judicial extenderá también acta sucinta.

\section{CONCLUSIONES}

La sustancial transformación que ha experimentado la organización y el funcionamiento de la Oficina Judicial, con la generalización de las comunicaciones electrónicas a través del sistema LexNet y de los documentos judiciales electrónicos, debiera culminar, de forma irreversible, en el establecimiento de sistemas eficaces de conservación y digitalización de las actuaciones procesales, que permitieran descongestionar los diferentes Juzgados y Tribunales y crear una oficina judicial ágil, rápida, con una correcta atención al ciudadano.

Algunas disposiciones reglamentaria apuntan en esta dirección, facultando a los órganos judiciales y a los responsables de los archivos judiciales para que utilicen los sistemas informáticos, telemáticos y electrónicos en la conservación, custodia y archivo de las actuaciones judiciales (art. 3 del Real Decreto 937/2003, de 18 de julio, de Modernización de los Archivos Judiciales).

Pese a esta amplia cobertura normativa, el legislador todavía no ha ordenado la «informatización» de los archivos judiciales con carácter general. En el momento histórico actual, la llevanza de los registros judiciales en soporte informático tiene por ahora sólo un valor auxiliar, pues no pasa de ser una regla de la propia organización interna de la oficina judicial, para facilitar el adecuado traslado de datos de una archivo a otro, o como medio de crear vehículos seguros de transmisión y recepción de determinados datos judiciales para uso exclusivo de los órganos jurisdiccionales.

La sustitución de los archivos en papel por el micro procesamiento y el almacenaje de datos electrónicos es ya una realidad próxima, como lo demuestra el nuevo y reciente Plan Estratégico de Modernización de la Justicia, aprobado por el Consejo de Ministros el día 18 de septiembre del presente año 2009. Hay que avanzar, sin embargo, un paso más en la línea de promover el advenimiento de los archivos judiciales exclusivamente digitales, pues la informatización de los ficheros de actuaciones judiciales no se impone solamente por una razón de reorganización interna de la oficina judicial, sino por una presión externa, a fin de facilitar, en general, el acceso de los ciudadanos a la documentación procesal, haciendo realidad el principio de publicidad de las actuaciones judiciales consagrado en la $\mathrm{CE}$ y en el art. 232 de la LOPJ. 